\title{
PIV and deformation measurements on the rotor blade of a rotating, scaled model wind turbine with flexible blades under tailored inflow conditions
}

\author{
Tom T. B. Wester ${ }^{1 *}$, Lars Kröger ${ }^{1}$, Apostolos Langidis ${ }^{1}$, Simon Nietiedt $^{2}$, Robin \\ Rofallski $^{2}$, Martina Goering ${ }^{2}$, Thomas Luhmann ${ }^{2}$, Joachim Peinke ${ }^{1}$, Gerd \\ Gülker $^{1}$ \\ ${ }^{1}$ University of Oldenburg, ForWind - Institute of Physics, 26129 Oldenburg, Germany \\ 2 Jade University of Applied Sciences, Institute of Applied Photogrammetry and Geoinformatics (IAPG), \\ 26121 Oldenburg, Germany \\ *tom.wester@uni-oldenburg.de
}

\begin{abstract}
Wind turbines face harsh inflow conditions when operating in the atmospheric boundary layer or in the wake of other wind turbines. The incoming velocity field can change within seconds due to the turbulent structures it contains, resulting in a rapid change of several degrees in the angle of attack for the rotating blade. Aerodynamics are hence rapidly altered, leading to changes of the occurring forces on the rotor. Such dynamic forces cause the blades to twist and bend, accelerating fatigue and reducing the lifetime of a turbine Spinato et al. (2009).

Isolating these effects and analyzing them in more detail, however, presents a challenging problem. It is difficult to reproduce actual inflow conditions sufficiently well in both experiments and simulation. In addition, measurements on the blades of a rotating model wind turbine pose major challenge.

In this study, this complex task is realized and a model wind turbine is investigated under three-dimensional tailored turbulent inflow. This experimental study combines the measurement of the occurring forces on the model wind turbine, detection of the blade deflections and turbine motions generated by the inflow, and the simultaneous measurement of the flow around the rotor blades using Particle Image Velocimetry (PIV).

Measurements are performed in a closed loop wind tunnel with an open test section at the university of Oldenburg. The outlet of used wind tunnel has a size of $3 \mathrm{~m} \times 3 \mathrm{~m}$. The length of the open test section is $30 \mathrm{~m}$. A picture of the setup is shown in Fig. 1(a), To generate realistic turbulent wind fields an active grid is used Neuhaus et al. (2020). The grid is attached to the nozzle (purple square) and consists of 80 individual movable shafts each equipped with diamond shaped flaps to change the blockage locally. Such grids can be used to reproduce very complex flow fields as often as desired Kröger et al. (2021).

To characterize the generated inflows a 2D ITASCA LDA system with an focal length of $2.6 \mathrm{~m}$ and sampling rates up to $2 \mathrm{kHz}$ from TSI is used (orange square) during experiments. Thus, a non-intrusive, but nevertheless simultaneous detection of the inflow is possible. For higher temporal resolution, additional independent hot-wire measurements at $20 \mathrm{kHz}$ were performed at the same location.

The MoWiTO 1.8 model wind turbine Berger et al. (2018) (yellow square) is exposed to the turbulent wind fields generated. The turbine with a rotor diameter of $1.8 \mathrm{~m}$ is characterized by a blade design with high deformability. The deformability of the blades, which is based on the NREL 5MW turbine, enables an even more realistic investigation of the influence of turbulence on the blade motion.

A multi-camera photogrammetry system is used to capture the three-dimensional blade motions across the entire rotor plane of the turbine. The system consists of four pco.dimax high-speed cameras (blue circles) and four high speed LED panels for illumination, mounted upstream of the wind turbine. To guarantee synchrony all used measurement systems are synchronized to the 12 o'clock position of the turbine at each rotation. The synchronization of the systems was already optimized in previous studies Nietiedt et al.(2019); Kröger et al. (2020).

The main focus of the presentation will be time-resolved stereoscopic PIV measurements. The light sheet used during measurements is aligned parallel to the wind tunnel floor. The field of view is chosen at the 12
\end{abstract}


o'clock position of the turbine at different span positions along the blade. For measurements two Phantom v1212 cameras are used with a sampling rate of $4 \mathrm{kHz}$ and a measurement duration of $25 \mathrm{~s}$. They are mounted on a support structure above and below the turbine hub (red circles).

An exemplary velocity field taken from the measurement at $70 \%$ span is shown in Fig. 1(b). The figure shows the evolving $u_{x}$ velocity component of the flow around the blade in a top view. The tailored turbulent inflow is coming from the left-hand side (x-direction). The rotor blade passes the flow perpendicularly along the $y$-direction from top to bottom of the picture.

The vector field nicely shows the influence of the rotor blade on the flow. The flow is accelerated by the blade in y-direction and thus follows the blade geometry. While the flow is accelerated at the leading edge of the blade, the flow at the trailing edge is reversed towards the inflow. In addition, the flow downstream of the rotor blade shows a clear velocity deficit due to the extracted energy relative to the flow upstream of the rotor plane. Further influences of the tailored turbulent inflow on the aerodynamics and the resulting blade deflections will be discussed in more detail in the presentation during the conference.

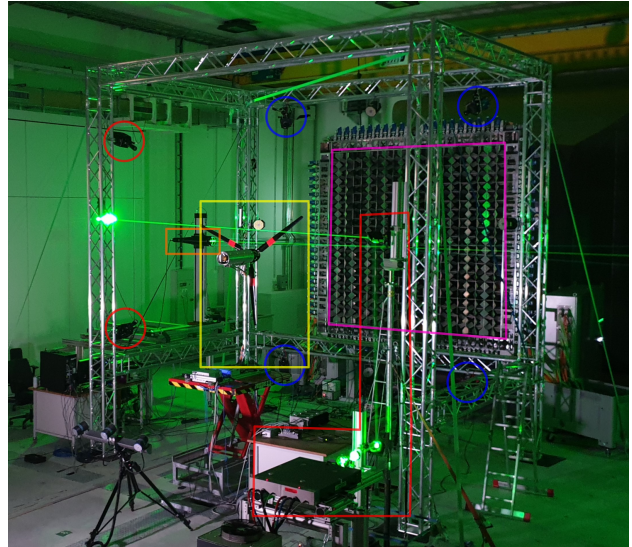

(a) Experimental setup showing the active grid marked in purple, the MoWiTO turbine marked in yellow, the 2D LDA system marked in orange, the Photogrammetry system marked in blue and the stereo PIV system marked in red.

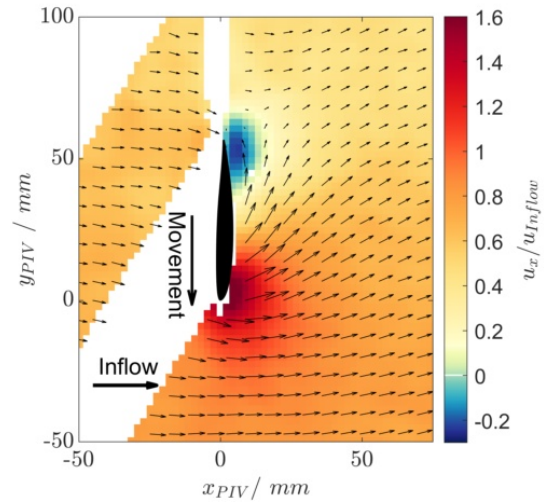

(b) Examplary velocity field taken from the PIV measurement at $70 \%$ span position. The colors represent the normalized $u_{x}$ component of the flow field. The inflow comes from the left and the rotor blade moves from top to bottom through the field. The blade cross-section is drawn here in black.

\section{References}

Berger F, Kröger L, Onnen D, Petrović V, and Kühn M (2018) Scaled wind turbine setup in a turbulent wind tunnel. Journal of Physics: Conference Series 1104:012026

Kröger L, Hölling M, Gülker G, and Peinke J (2021) Taming chaos with active grids-reproducibility in turbulent wind tunnel experiments. arXiv preprint arXiv:210104420

Kröger L, Wester T, Langidis A, Nietiedt S, Göring M, Luhmann T, Peinke J, Hölling M, and Gülker G (2020) Experimental study of fluid-structure interaction at a model wind turbine blade using optical measurement techniques. in Journal of Physics: Conference Series. volume 1618. page 032025. IOP Publishing

Neuhaus L, Hölling M, Bos WJ, and Peinke J (2020) Generation of atmospheric turbulence with unprecedentedly large reynolds number in a wind tunnel. Physical Review Letters 125:154503

Nietiedt S, Goering M, Willemsen T, Wester T, Kröger L, Guelker G, and Luhmann T (2019) Measurement of fluid-structure interaction of wind turbines in wind tunnel experiments: Concept and first results.. International Archives of the Photogrammetry, Remote Sensing \& Spatial Information Sciences

Spinato F, Tavner PJ, Van Bussel G, and Koutoulakos E (2009) Reliability of wind turbine subassemblies. IET Renewable Power Generation 3:387-401 